\title{
Demand Heterogeneity and the Adoption of Platform Complements
}

\author{
Joost Rietveld $^{1}$ \\ Rotterdam School of Business, Erasmus University \\ Burgemeester Oudlaan 50 Mandeville (T) 7-41 \\ 3062 PA Rotterdam, the Netherlands \\ Tel: +31(0)10408 1996 \\ E-mail: rietveld@rsm.nl

\section{J.P. Eggers} \\ Stern School of Business, New York University \\ 40 West Fourth Street Tisch 715 \\ New York, NY 10012 \\ Tel: +1 (212) 998-0874 \\ Email: jeggers@stern.nyu.edu
}

This version:

January, 2016

\footnotetext{
${ }^{1}$ Corresponding author: rietveld@rsm.nl

We are greatly indebted to Melissa Schilling for her feedback and actionable advice. We also thank Masakazu Ishihara, Rob Seamans, Stefan Haefliger, David Nieborg, Anil Doshi, Cristiano Bellavitis, the participants of the 2013 NYU Columbia Doctoral Conference, and the participants of the 2014 Platform Strategy Research Symposium. We thank three research assistants for their data collection efforts as well as Andy Webb for his insights on the UK video games industry. All mistakes are our own.
} 
Abstract. This paper offers a demand-based theory of how platform maturity affects the adoption of platform complements. We argue that differences between early and late adopters of the platform include willingness to pay for the platform-and-complement bundle, risk preferences, preference for novelty, and search behavior. These differences create heterogeneous demand conditions for complements that affect both average complement performance and variance in the types of complements that are more or less successful. Using a novel dataset of 2,921 sixth-generation console video games, we find that platform maturity has a negative relationship on video games' unit sales. Furthermore, as the platform matures, we find that the sales disparity between new intellectual property (IP) games and games based on existing video game properties or media tie-ins grows to the detriment of new IP games. We find that the sales disparity between superstar games and flops also widens as the platform matures. These effects are accentuated by the introduction of a next generation platform, which further skews the complement's customer pool as early adopters migrate away from the current generation platform. Robustness tests that control for unobserved heterogeneity help rule out alternative explanations and support our argument that these performance implications are truly driven by heterogeneity in demand.

Keywords: platform markets, complementary goods, demand-perspective, industry evolution, video games 
"I understand the manufacturers don't want [new platforms] too often because it's expensive, but it's important for the entire industry to have new consoles because it helps creativity. It's a lot less risky for us to create new IPs when we're in the beginning of a new generation."

Yves Guillemot, CEO Ubisoft (Morris, 2012)

\section{Introduction}

In two-sided markets such as video games, operating systems and newspapers, the availability of popular complements influences platform success (Gawer, 2014; Schilling, 1998; 1999; 2002; Wareham, Fox \& Giner, 2014). For example, the popular video game Tetris led to Nintendo's dominance in the handheld video game market with the Game Boy in the early 1990s. Similarly, the American Broadcasting Company $(\mathrm{ABC})$ quickly realized the importance of quality content in persuading viewers to migrate from black-and-white to color TVs in the early 1960s. Licensing exclusive Disney content helped ABC attract a critical mass of color TV adopters.

The influence of complements on platform performance inspired researchers on two-sided markets (Rochet \& Tirole, 2003; 2006), platform markets (Schilling, 1998; 1999; 2002), and technology ecosystems (Adner \& Kapoor, 2010) to focus on how changes on the complements side affect consumer demand for platforms. The central argument revolves around indirect network effects: An increase in the number of complements supporting a platform results in increased platform adoption by end-users (Clements \& Ohashi, 2005; Parker \& Van Alstyne, 2005; Stremersch, Tellis, Franses \& Binken, 2007). Recent studies have also looked at the heterogeneous effect of different types of complements on platform adoption (Cennamo \& Santalo, 2013; Corts \& Lederman, 2009; Kim, Prince \& Qui, 2014; Landsman \& Stremersch, 2011). For example, Binken and Stremersch (2009) find that superstar complements complements of high quality and high popularity - are especially important for platform success.

While this research shows that the evolution of the complement market affects platform performance, the converse has received little attention - how does the evolution of the platform market affect the performance of complements? One salient aspect of platform evolution for the performance of complements is relatively intuitive - since the only potential adopters of a given complement will be 
those consumers who have already adopted the platform, well-established platforms provide a larger potential market for complements. ${ }^{2}$ But the implications of platform evolution go beyond simply adding more potential consumers for complements. Important and systematic differences between early and late adopters of a platform mean the type of consumers in the pool of potential adopters shifts over time (Von Hippel, 1986). Early and late adopters may have different preferences and exhibit different behaviors (Rogers, 2003), which may also impact the performance of different types of complements over time. This paper explores how the evolution of a platform from inception towards maturity affects performance outcomes for complementary products. We explore both the average effect on complements, as well as which types of complements are more or less affected. This question is distinct from traditional considerations of technology lifecycles or dominant designs (Abernathy \& Utterback, 1978; Dosi, 1982; Utterback \& Abernathy, 1975) because the lifecycle of a given complement is not independent, but instead is embedded into the larger lifecycle of its platform. In video games, for example, the lifecycle of an average game is compressed within three to six months (Binken \& Stremersch, 2009; Tschang, 2007), while video game consoles have an average lifecycle of seven years. Thus, complements launched early in a platform's lifecycle face an audience of mostly early adopters, while later launching complements face an audience comprised of a mix of early and late adopters. The innovation diffusion literature suggests that early adopters of an innovation (such as a new platform) are qualitatively different from late adopters. Late adopters are typically risk-averse, respond to relatively basic information when searching, and have a lower willingness to pay, while early adopters actively seek out product information and are more willing to take risks (Cabral, 1990; Rogers, 2003). We build on this logic to theorize that demandside user heterogeneity (based on the adopters of the platform) will affect both the level of success of complements as well as the specific types of complements that will be more successful early or late in the platform's lifecycle.

To analyze these dynamics, we use a dataset of 2,921 video games released in the UK between

\footnotetext{
${ }^{2}$ Whether this is good or bad for complements depends on how many competing complements are attracted to a successful platform, as noted by Venkatraman \& Lee (2004).
} 
2000 and 2007 on three competing platforms spanning the entire sixth generation of consoles. The market for video games has often been described as a "canonical" example of a two-sided platform (Cennamo \& Santalo, 2013; Clements \& Ohashi, 2005; Dubé, Hitsch \& Chintagunta, 2010). Worldwide sales for the video game industry reached $\$ 100$ billion in 2014 , with over $70 \%$ of sales coming from video games and the remainder from hardware and accessories (ESA, 2013; Gartner, 2013). Video game consoles are a particularly fitting setting given their generational nature. Hardware systems have clearly demarcated beginnings and ends, and the timing of competing consoles that are part of the same generation typically occurs within an eighteen months timeframe. The data allow us to control for and rule out a number of competing explanations - the effect of competition among complements, the effect of the impending introduction of a new generation game console, and unobserved heterogeneity at the complement level.

This paper contributes in three primary areas. First, the paper contributes to the small but growing body of work on platform competition that focuses on complementors instead of platform owners. Existing work has already explored the implications of competition among complementors (Boudreau \& Jeppesen, 2014; Boudreau, 2012; Venkatraman \& Lee, 2004). ${ }^{3}$ By articulating how platform evolution affects the innovation and new product introduction strategies of complementors, our approach links the literature on platforms and complementors with that on innovation strategy and industry evolution (Klepper, 1997; Ahuja, Lampert \& Tandon, 2008). Second, by considering the impact of consumer heterogeneity this paper contributes to the strategy research on demand-based perspectives (Adner \& Kapoor, 2010; Adner \& Zemsky, 2006; Priem, 2007). The fact that a complementor's potential customer pool is relatively exogenously given by the efforts of the platform owner represents a different perspective on how demand-related factors affect firm innovative performance. Finally, our theory and findings also have important implications for platform owners. Given the popularity of platform- and ecosystem-based business models, organizational researchers have been interested in what ecosystem

\footnotetext{
${ }^{3}$ Following Gawer (2014) and Gawer \& Cusumano (2014) we use the terms 'provider of complementary goods' and 'complementor' interchangeably. Brandenburger, Nalebuff and Maulana (1996) classify products as complements when greater sales of one product increase demand for the other (e.g. video game consoles and video games).
} 
governance and management strategies will be most successful for the platform (Cennamo \& Santalo, 2013; Wareham et al., 2014). This study identifies specific types of complements that platform owners should encourage to enter during different stages in the platform's lifecycle in order to be most successful.

\section{Theory Development \& Hypotheses}

In this section we develop our theory of how heterogeneity among the consumers who adopt a platform has implications for the performance of innovative complementary products. We first outline stylized differences between early and late adopters of an innovation. We then discuss the implications of these differences in the context of two sided markets before offering specific hypotheses.

\section{Differences between Early and Late Adopters of Technologies and Platforms}

Research on the diffusion of technologies has long asserted that there are key differences between the early versus later adopters of a given technology. Adopters of an innovation can be placed on a continuum ranging from early adopters ("innovators") to late adopters ("laggards"). ${ }^{4}$ We recognize that adopter types are actually continuous, but for sake of exposition we focus on the distinction between two groups - early adopters and late adopters. While Rogers (2003) outlines many differences between early and late adopters that include factors such as age and gender, we focus here on four factors that have particular implications for our theory development: Willingness to pay, risk preferences, preferences for novelty, and search processes. We discuss each below.

First, early adopters of a technology (including a platform) will be more willing to spend time and money on the platform and its complements than later adopters. The underlying logic is that early adopters make adoption decisions without knowing whether the platform will emerge as the dominant

\footnotetext{
${ }^{4}$ Diffusion processes follow a normal distribution where innovativeness is partitioned in standard deviations from the average adoption time (Rogers, 2003). Similar to a platform's lifecycle, cumulative adoption follows an Sshaped curve where the mean denotes the inflection point. Rogers identifies five adopter categories: Innovators (2.5\% of all adopters); early adopters (13.5\%); early majority (34\%); late majority (34\%); and, laggards (16\%). These categories are exhaustive in that they include all adopters of a given innovation, but exclude non-adopters. It is important to note that the commonly used adopter categories are a conceptual tool and that the underlying dimensions distinguishing early adopters from late adopters are, in fact, continuous.
} 
design, oftentimes paying an even higher price for the platform than do late adopters (Schilling 1998, 1999). Cabral (1990) offers a model of platform adoption that concludes that early adopters must have a higher willingness to pay for the technology since they adopt without the benefits of certainty. The rate of adoption by subsequent users (both end-users and producers of complementary goods) strongly affects the value of a platform, but it is often unknown to early adopters which rival platform will eventually enjoy the greatest adoption rate (Arthur, 1989; Katz \& Shapiro, 1994). Karshenas and Stoneman (1993) build on this perspective to suggest a "rank effect" process, whereby the potential adopter with the highest preference adopts first, and then subsequent adopters who have lower valuations. Empirically, Kretschmer and Grajek (2009) show this phenomenon in the mobile network industry, where early adopters of mobile technologies use the technology much more intensively than later adopters (see also Golder and Tellis, 2004). In general, prior research has established that early adopters of a technology tend to value the technology more highly than later adopters.

Second and relatedly, earlier adopters are typically less risk averse than late adopters. Geroski's (2000) review of the innovation diffusion literature notes that a number of studies have explored differences in risk attitudes between early and late adopters, and used these differences to explain the adoption curve of new technologies. Leonard-Barton (1985) notes that this effect may be due to late adopters often having less disposable income, and so have more at risk. The overall belief is that early adopters are often less concerned about risk when making adoption decisions.

Third, early adopters are likely to have a stronger preference for novelty and exploration than later adopters. For example, prior research on computer operating systems (Chau \& Hui, 1998) found that early adopters tended to be consumers that generally sought out novelty and wanted to experiment with new products. This preference for and tolerance of novelty is likely what leads these consumers to be early adopters of a technology in the first place - they derive utility from exploring and experiencing a new technology.

Finally, early adopters engage in different search patterns than do later adopters. Early adopters frequently seek information from external sources and therefore have greater innovation-specific 
knowledge than do later adopters. This is in part because, early on, there may not be consensus information about the quality of the new product, and certainly not information available from many close personal sources (i.e., friends and colleagues) who have tried the new technology. In the case of platforms, early adopters may have little information on the variety of complements available on the platform, or the eventual size of its installed base (Clements \& Ohashi, 2005; Gretz \& Basuroy, 2013), meaning that they cannot rely on these simple signals. By contrast, late adopters have a large volume of information available to help them make adoption decisions. These adopters can thus be relatively passive, and rely on readily available signals of quality such as provided by word-of-mouth and social contagion in making their adoption decisions (Haigu \& Spulber, 2013). Thus, we expect early adopters to search broadly for information, while later adopters tend to focus on easily available high quality signals when making decisions.

\section{Implications for Complementors}

These four factors - willingness to pay, risk preference, novelty preference, and search behavior - all differentiate early from late adopters of a given technology or platform. Here we discuss how these differences may affect the performance of complementary products available on the platform.

Translating these factors that define early and late platform adopters to complementors entails an important assumption - that these characteristics are stable. Thus, we have to assume that if a person was novelty-seeking when they were the early adopter of a platform, they will continue to be novelty-seeking at least in the domain of the platform and its complements. This seems like a reasonable assumption, as consumers do not buy the platform alone, they value the platform-complements bundle as a whole (Schilling, 1999). Thus, any personal characteristics that affected their decision to purchase the platform will likely spill over to their purchase decisions around the complements. In addition, many of the studies articulating differences between early and later adopters have found that the factors distinguishing the consumers in one technology were consistent across other technologies. For example, early adopters that sought out the novel aspects of online travel booking also tended to be consumers that were early adopters of other Internet behaviors, and for similar reasons (Kah, Vogt \& MacKay, 2008). This, combined with 
research showing that factors like risk preferences tend to be relatively stable for a given person over time (Andersen, Harrison, Lau \& Rustrom, 2008; Harrison, Johnson, McInnes \& Rustrom, 2005), suggests that it is reasonable to assume that if the four factors discussed above distinguished early adopters of the platform from late adopters, then these same characteristics might also inform their interaction with complements on the platform.

As a result of the fact that the complementor draws its pool of potential customers from the pool of platform adopters, this means that differences in consumer preferences (such as those discussed above) will have an impact on the success or failure of any given complement. Thus, a complement that faces a pool of potential adopters that are primarily comprised of early adopters of the platform will face consumers with a higher willingness to pay, who are more risk seeking, who prefer novelty, and who are willing to "dig deep" when doing research to figure out which complements to adopt. By contrast, those complements that face a pool of users primarily comprised of later adopters of the platform will face the opposite situation - consumers with a lower willingness to pay, who are risk averse, who dislike novelty, and who gravitate towards a single, high-reliability signal of complement quality. Practically, given that (a) complement life cycles are relatively short compared to longer platform life cycles, and (b) that early adopters adopt early by definition, this means that complementors launching complements in the early stages of a platform's maturity and evolution will face a pool comprised largely of early adopters, while those that launch later in the platform's lifecycle will face a mixed customer pool, likely weighted towards later adopters since that population is typically seen as larger than that of the early adopters (Rogers, 2003). This core insight provides the underlying theory behind the hypotheses that we offer below.

\section{Hypotheses}

Given the theory outlined above, deriving specific and testable hypotheses is relatively straightforward.

Here we offer one hypothesis that builds off the assertion that early adopters have a higher willingness to pay, two hypotheses that build on risk and novelty preferences, and two that build on differences in search behavior (and risk preferences). 
First, the fact that early platform adopters may value the technology of a platform higher has implications for the platform, but also for the producers of complements. For most platforms (e.g. video games, computers, mobile phones) users do not purchase the platform for itself, but for the ability to use value creating complements (Schilling 1999; 2002). This is illustrated in the market for video games where over $70 \%$ of $\$ 21 \mathrm{bn}$ sales revenue in the US in 2014 was spent on games, and the remainder on video game consoles and accessories. Thus, we expect the higher valuation of the technology bundle of platform-plus-complements to mean that early adopters are more willing to spend money and time on complements than later adopters. The result is that we expect that complements launched earlier in the platform's lifecycle will be more successful than ones launched later. ${ }^{5}$ We thus argue that:

Hypothesis 1. As platforms mature, the average adoption (i.e., sales) of complements will decrease.

Second, late adopters of platforms not only allocate less money and time and thus purchase fewer complements, they also enjoy different types of complements. This can be understood through the example of casual gamers and hardcore gamers in the video game industry. More so a continuum rather than a dichotomy, casual gamers overlap with what Rogers (2003) defines as late adopters while hardcore gamers resemble the depiction of early adopters. Consider the following quote by video game theorist Jesper Juul: "The stereotypical casual player has a preference for positive and pleasant fictions, has played few video games, is willing to commit small amounts of time and resources toward playing video games, and dislikes difficult games.” (Juul, 2010; p. 29; emphasis in original) And: "The stereotypical hardcore player has a preference for emotionally negative fictions like science fiction, vampires, fantasy and war, has played a large number of video games, will invest large amounts of time and resources toward playing video games, and enjoys difficult games" (Juul, 2010; p. 29; emphasis in original).

\footnotetext{
${ }^{5}$ Prior research has identified two key effects that platform evolution may have on the performance of complements. First, platform maturity typically brings in more consumers, which increases the success of complements (Katz \& Shapiro, 1986; 1994). Second, the increase in consumers draws in competing complements, which decreases the success of any given complement (Boudreau, 2012; Wareham et al., 2014). We will control for these two effects empirically, to suggest that the remaining decrease in performance predicted in $\mathrm{H} 1$ is based on evolution of consumer preferences in the potential adopter pool.
} 
This distinction builds off the differences in risk and novelty preferences that we outlined earlier. Given that complementors face a decision between producing novel and exploratory complements versus derivative and more familiar complements (Tschang, 2007), ${ }^{6}$ it becomes apparent that novel complementors will be especially unsuccessful as the platform evolves and the user base is comprised more and more of late platform adopters. Novel complements are shrouded by uncertainty and are unprecedented, thus imposing valuation ambiguities to end-users on the platform (Priem, 2007). This makes them both high risk and highly novel, which means they will appeal more to early adopters than to late adopters. It is for this reason that the adoption of novel complements is disproportionately affected by the evolving composition of the platform base. The paper's second hypothesis therefore is:

Hypothesis 2. As platforms mature, the adoption of novel complements will decline at a faster rate than non-novel complements.

Third, differences in search behavior and risk preferences between early and late adopters will also likely affect the relative performance of the most and the least popular complements on the market (i.e., affecting the variance in performance outcomes). That there is a disparity between popular ("superstar") complements and less popular ("flop") complements is relatively obvious. This fact is wellillustrated by the example of Grand Theft Auto V. The hit game sold more copies in its opening week in the UK than the opening weeks for the next six most popular franchises combined (Dring, 2013). What is important is that the pool of early adopters is more likely to search broadly for potential complementors to purchase and should be less concerned about the risks of adopting a complement that they end up not liking (McPhee, 1963) - both of which should diminish the disparity between superstars and flops. By contrast, late adopters should be more risk averse and more inclined to follow the social cues of the market, which should increase the success of superstar complements. Empirically this tendency towards the dominance of a few complementors in more mature markets has been supported in the markets for online DVD sales (Elberse \& Oberholzer-Gee, 2008), as well as online recommender systems (Fleder \&

\footnotetext{
${ }^{6}$ For example, video game developers are faced with the tension between producing games that are based on new, or original, intellectual property (IP) and derivatives of existing video franchises ("sequels") or external media adaptations such as Hollywood films.
} 
Hosanagar, 2009). Our third hypothesis, therefore, is that the gap in sales between popular and less popular complements will increase as the platform evolves, as more risk averse users who seek less deeply adopt the platform:

Hypothesis 3. As platforms mature, the sales disparity between popular and non-popular complements will increase.

Finally, the underlying logic of the above discussion suggests that complementors introduced early in the platform's evolution will face an audience of early adopters, while those introduced later will face a more mixed audience. There is one additional factor in many platform markets that will affect the balance between early and late adopter-type consumers in the market - the introduction of next generation platforms. The idea of a next generation platform competing with and eventually replacing the existing platform is a common phenomenon in video games, mobile phones, and other platform markets (Adner \& Kapoor, 2015; Adner \& Snow, 2010). Prior research suggests that due to the relative stability of preferences, the early adopters of one generation are likely to be early adopters of the next generation (see Huh and Kim, 2008, for an example in Korean mobile phones). This would mean that, as the next generation platform is introduced, the share of early adopter-type consumers still active in the old generation platform will decline as these consumers move to the new platform. This migration will accentuate the effects discussed above for $\mathrm{H} 2$ and $\mathrm{H} 3$, leading us to offer parallel hypotheses about the effect of next generation platform sales:

Hypothesis 4. As the next generation platform launches and gains adopters, the adoption of novel complements will decline at a faster rate than non-novel complements.

Hypothesis 5. As the next generation platform launches and gains adopters, the sales disparity between popular and non-popular complements will increase.

\section{Research Setting and Methodology}

\section{The Market for Console Video Games in the United Kingdom (2000-2007)}

We focus on the sixth generation video game consoles in the United Kingdom. The UK market for video games is disproportionate to the country's size in terms of cultural and economic relevance (Johns, 2006). In 2010, the UK market for video game consoles represented about $20 \%$ of the global market (IDG, 
2011). We chose the sixth generation as it was the most recent generation for which data on a completed platform lifecycle was available at the time of data collection. Rival platforms in this generation are Sony's PlayStation 2 (PS2), Microsoft's Xbox and Nintendo's GameCube. Sony was first to enter the sixth generation in November 2000 followed by Microsoft and Nintendo in March and May of 2002, respectively. Sony's PS2 was the dominant platform in this generation with over 9 million units sold in the UK. By the end of the sixth generation, Sony dominated the market with $74 \%$ market-share followed by Microsoft (17\%) and Nintendo (9\%). The seventh generation game consoles was initiated by the introduction of Microsoft's Xbox 360 in November 2005, followed by Nintendo's Wii in December 2006, and Sony's PlayStation 3 in March 2007 (see Table 1).

\section{--- INSERT TABLE 1 HERE ---}

The video game industry is an appropriate location in which to explore our theory for three reasons. First, the setting is clearly a platform market. More than once, the console video game industry was labeled a "canonical" example of a two sided platform (Cennamo \& Santalo, 2013; Clements \& Ohashi, 2005; Dubé et al., 2010). The industry includes platform owners that create the infrastructure for publishers to release games, and end-users who purchase consoles to enjoy the video games released on the platform. Platform owners generate revenues both by selling consoles and through royalty payments on games sold. In a typical "razors and blades" model, platform owners often sell consoles at a loss to increase end-user adoption, especially early in the platform's lifecycle. Most video games are produced and commercialized by independent third party publishers, though platform owners do engage in some first-party game development. Second, home video game consoles have clearly defined beginnings and ends, which aides us in our operationalization of platform maturity. Given the substantial investments and long recoupment trajectories, platform owners typically release new platforms every five to eight years. Third, there is a constant supply of video games with a rich variation in terms of types and market performance throughout a console's lifecycle (discussed in more detail below).

The most popular franchises in our data include Grand Theft Auto (Take 2 Interactive), FIFA (Electronic Arts), Need For Speed (Electronic Arts), Halo (Microsoft), and Super Mario (Nintendo). The 
most popular game was Grand Theft Auto: San Andreas, which was released in November 2004 and sold in excess of 2.3 million units on Sony's PS2. Highly innovative games were received with mixed reactions: Nintendo successfully launched its new intellectual property, Pikmin, early in the lifecycle of its floundering GameCube platform (June 2002). The real-time strategy game sold nearly 70,000 units and received rave expert evaluations averaging 89/100. By contrast, the now defunct THQ released the innovative Psychonauts close to the end of the PS2's lifecycle (February 2006). The game sold a mere 12,000 units despite rave expert scores $(88 / 100)$. These examples illustrate the variance in performance that exists for innovative video games despite similarity in quality as determined by expert critics.

\section{Data and Measures}

We built a novel and comprehensive dataset of sell-through data for all video games released in the UK across the three sixth generation game platforms. The data are comprehensive in that all console video games released in the UK are included. Video game and platform sell-through data (including release dates, firm information, and genre information) come from a series of proprietary databases provided by one of the platform owners in the UK. Quality measures were hand-collected from online review aggregation database Metacritic.com/games. Information on games' innovativeness were hand-collected by three research assistants and is elaborated on in more detail below. Additional data for instrumental variables were collected from the US Bureau of Labor Statistics. Table 2 provides an overview of the study's main variables, and we discuss them below.

\section{--- INSERT TABLE 2 HERE ---}

\section{Dependent Variable}

Complement adoption is operationalized as the video game's platform-specific total unit sales. ${ }^{7}$ Unit sales data include point-of-sale transactions for approximately $90 \%$ of all (online) retail transactions in the UK between November 2000 and November 2007. Data on game sales are complete until January 2012.

Given that video games have very short product lifecycles -most games sell the bulk of their units within

\footnotetext{
${ }^{7}$ Measuring the success and adoption of video games through total sales in GBP produces similar results.
} 
three to six months of being on the market (Binken \& Stremersch, 2009, Tschang, 2007) - we are not concerned with structural biases caused by unintentional right censoring of our dependent variable for games released near the tail-end our data. In addition, given that our primary interest involves differences between (for example) new and existing IP games, all games released at the same time would be subject to the same (if any) biases.

We focus on platform-specific unit sales because many games "multi-home", meaning they are launched on multiple platforms at the same time (Landsman \& Stremersch, 2011). Given that our theory focuses on the underlying maturity of the video game platform and competing platforms may be at different levels of maturity at the same date, using platform-specific sales allows us to capture different effects by platform. In fact, in additional robustness tests discussed below, we exploit this subsample of multi-homing games for a game fixed-effects estimation allowing us to rule out unobserved heterogeneity at the game level, instead focusing on the variance that exists on the platform side. As games' unit sales tend to be highly skewed, we log transform the variable.

\section{Independent Variables}

Our theory of demand heterogeneity in platform adopters generated a set of testable propositions about the effect of platform maturity on complement adoption. In order to facilitate a straightforward comparison between the three platforms' installed bases, we compute a normalized measure of platform maturity at time $t$ such that:

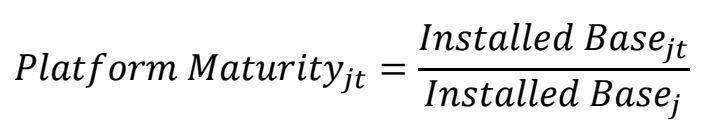

The numerator measures platform $j$ 's installed base in month $t$ of a focal game's release. The denominator denotes the cumulative number of platform adopters on platform $j$ at the end of its lifecycle. Previous studies on platform competition have adopted a similar approach (see Stremersch et al., 2007). Following earlier work on two-sided platforms in the console video game industry, we mark the end of a console's lifecycle when monthly platform sales in the UK drop below 1,000 units, or when we observe a month without any game introductions at the platform level (Binken \& Stremersch, 2009; Cennamo \& 
Santalo, 2013; Landsman \& Stremersch, 2011). ${ }^{8}$ The resulting variable ranges between zero and one, which linearizes the S-shaped platform adoption curve allowing for a more straightforward interpretation of platform maturity's effect on game sales.

Hypothesis 2 tests the differential effect of platform maturity on novel complements' and nonnovel complements' adoption. In the market for video games, novel games are games based on an entirely new, or original, intellectual property (IP). In line with Tschang (2007), we operationalize new IP as games that are not adaptations of existing media licenses (e.g. motion pictures or TV series) and are not a derivative or a sequel of an existing video game franchise. The aforementioned Pikmin and Psychonauts are examples of games based on new IP. Data on IP originality were hand-collected. Two graduate students and an industry expert consulted video games' box covers and other online sources to understand if a video game was based on a new intellectual property.

New IP is a binary variable that takes the value of 1 if a video game is based on a new IP and 0 otherwise. In our sample, $29 \%$ of all video games are based on new IP. This statistic corresponds with generally accepted statistics of non-imitative or really new innovations in a market (Kleinschmidt \& Cooper, 1991). Figure 1 displays the distribution of video game introductions per platform and the ratio of new IP introductions by platform maturity. ${ }^{9}$ The figure illustrates that, across different levels of platform maturity, there is sufficient variance in terms of the number of games entering each platform as well as the ratio of video games that are based on new intellectual property.

\footnotetext{
${ }^{8}$ Note that in their study of the US console video game industry in the same timeframe Binken \& Stremersch (2009) and Landsman \& Stremersch (2011) use a threshold of 5,000 consoles sold to lineate the end of a console's lifecycle. Market analysis firm IDG (2011) estimates that the UK market for video game consoles in 2010 was approximately $20 \%$ of the US market, hence the threshold of 1,000 units. Neither of the two criteria is fully met for the PS2 by the end of the available data on hardware sales (November 2007). This forces us to right-truncate PS2's lifecycle, which may introduce an upward bias in the results.

${ }^{9}$ The supply of video games is disproportionate to the growth of the installed base towards the tail-end of the platform lifecycle. Game publishers are myopic to a slowing down in the growth of the installed base: Even when the rate of new platform adopters levels off, games publishers keep releasing new games to exploit the existing installed base. This observation is consistent with Clements \& Ohashi (2005) who study the US video game industry (1994-2002). Another potential explanation is that publishers make their seventh generation video games backwards-compatible with sixth generation video games to tap into a large pool of end-users and smoothen their transition into the next generation. We assess the implications of this alternative explanation in the robustness testing section.
} 


\section{--- INSERT FIGURE 1 HERE ---}

Hypothesis 3 deals with the comparison between "star" and "flop" complements. We investigate this by assessing whether the effect of platform maturity is different at different ends of the complements adoption distribution. Thus, we do not need to introduce any new variables to test $\mathrm{H} 3$.

Hypotheses 4 and 5 consider the effect of the next generation platform as a substitute for platform maturity in how platform-side dynamics affect complement-side outcomes. Next generation IB measures the size of a next generation platform's installed base at the time of a focal game's market launch. We link each next generation platform to its direct predecessor (e.g. Xbox 360 for games released on Microsoft's Xbox) and count the number of consoles sold at the time of the focal game's release. There are nine months where the PS2 co-existed alongside the PS3, 14 months where the Xbox co-existed alongside the Xbox 360, and no months in which the GameCube co-existed alongside the Wii. We logtransform this variable to fit a normal distribution.

\section{Control Variables}

In selecting control variables, we focused on important variables that have been shown to influence complements' performance. These controls allow us to rule out specific alternative explanations for the observed impact of platform-side dynamics that form the basis of our theory. Given the practical and theoretical relevance of network effects in platform markets, we test for the existence of direct and indirect network effects on video games' sales performance. Platform sales measures the number of consoles sold at the platform level in month $t_{j}$ of a focal game's release. We introduce a one month lag to eliminate reversed causality. To fit a normal distribution we take the log-transformation. Genre competition controls for same-side or direct network effects on video games' sales. Genre competition counts the number of same genre video games (relative to the focal game) entering a platform in month $t_{j}$ at the time of a focal game's release. Here too, we control for reverse causality by introducing a one month lag. In addition to the inclusion of rival games entering the platform and the number of consoles sold we include the ratio of the installed base at the time of a focal game's release to the stock of games 
available on the platform (users-to-games) to control for fluctuating demand/supply levels over a platform's lifecycle. To facilitate interpretation of this coefficient we measure the installed base in units of thousand.

At the game level we control for a video game's quality as measured by independent expert critics. We obtained quality measures from the video games section of review aggregation database Metacritic.com. We use the average expert review scores for every game at the platform-game level to create a categorical variable that indicates whether a game's review score is high $(\mathrm{n}=780)$, medium $(\mathrm{n}=$ 1148), low $(\mathrm{n}=158)$, or missing $(\mathrm{n}=835)$. In accordance with Metacritic's colored grading scheme that ranges from 0 to 100 , quality scores equal to or above 75 - scores that are denoted as "generally favorable" and "universal acclaim" - are marked as high. Similarly, scores that are below 50 - games that are met with "generally unfavorable reviews" and "overwhelming dislike" - are marked as low (Metacritic, 2015). We use games with missing quality scores as the base category in our regression models. We choose to use this categorical measure of quality as exploration of the data suggests strong threshold effects, with variance in scores above or below the threshold having minimal impact on sales. However, our results are fully robust to a continuous measure of game quality.

To control for systematic variation in consumer preferences by genre, we include game genre fixed effects. ${ }^{10}$ The video game industry is also characterized by strong seasonality as many blockbuster games are released in the weeks leading up to Christmas when demand for entertainment goods spikes (Einav, 2007). To control for this seasonality in demand and supply we include eleven month-of-release fixed effects using January as base level. Lastly, time invariant differences at the platform level may also structurally affect game sales, so we include two platform fixed effects with Sony's PS2 being the base category. High collinearity between the progression of time and the platform maturity measure prevents us from including year fixed effects. Additionally, since our dependent variable is the game's cumulative unit sales, it is not very useful to control for games' prices in our models (i.e. producers will strategically

\footnotetext{
${ }^{10}$ There are 15 genres in the data: action (base), fighting, graphic-adventure, music, non-game, platform, puzzle,
} racing, real game, role playing game, shooter, simulation, skateboarding, sports, and war. 
adjust their prices to influence demand over the game's lifecycle). This is reinforced by the fact that console video games are brought to market with mostly homogenous recommended retail prices imposed by the platform owner. We address both concerns in the robustness testing section by including macroeconomic controls and using an alternative dependent variable (i.e. cumulative revenues).

--- INSERT TABLE 3 HERE ---

Table 3 lists descriptive statistics for the study's covariates. Even though VIF statistics are well below conventional limits, we note that there exists a high pairwise correlation between Platform sales and Users-to-games (0.72). Our findings are robust to alternative specifications where we exclude the users-to-games measure. The final sample comprises 2,921 observations released across 190 consolemonths.

\section{Analytical Approach}

Primary empirical analyses rely on Ordinary Least Squares (OLS) regressions of the form:

$$
\ln (\text { Unit sales })_{i j}=\beta 0+\beta X_{i j}+\varepsilon
$$

Where $\beta X_{i j}$ represents a vector of variables including Platform maturity, In(Next generation IB), New IP, their interactions, and the control variables specified above. The models estimate the log of cumulative unit sales for game ${ }_{i}$ on platform ${ }_{j}$. We address concerns about endogeneity and unobserved heterogeneity when discussing alternate explanations and robustness checks below.

To identify the sales disparity between superstar games and flops we use weighted least absolute deviation estimators, or quantile regressions (Koenker \& Bassett, 1978). Quantile regressions are apt estimators when the researcher is interested in how independent variables affect various points in the distribution of the dependent variable. Recent studies have used quantile regressions to estimate effects on observations residing in the tail-end of the distribution (Boudreau et al., 2011; Elberse \& Oberholzer-Gee, 2008). By jointly estimating and comparing coefficients for observations in the lower quantiles and higher quantiles of the dependent variable, we can make inferences about the effect of platform maturity on the sales disparity between popular and non-popular video games. We report outcomes to estimations 
Quant $_{\tau}$, where $\tau=10$ estimates non-popular games and $\tau=90$ estimates popular video games. Our findings are robust to alternative thresholds for popularity. We compare the coefficients of both estimations by jointly estimating interquantile-range regressions. The estimated variance-covariance matrix is obtained via bootstrapping 100 replications. The "coefficients" reported in model 3 of Table 5 denote the differences between the coefficients of Models 1 and 2 of Table $5\left(\right.$ Quant $_{90}-$ Quant $\left._{10}\right)$ and the extent to which they are significant.

\section{Results}

\section{The Effect of New IP, Platform Maturity, and Next Generation Platforms on Game Sales}

Table 4 shows the results of the OLS regressions that test H1, H2, and H4. Model 1 includes only the various fixed effects, Model 2 adds controls, Model 3 adds Platform maturity testing H1, and Models 4-6 add interaction effects to assess $\mathrm{H} 2$ and H4. In Model 7 we explore the possibility that producers' choice to develop novel IP games is non-random by estimating a treatment effects model. We explain the underlying logic for Model 7 in the section about alternative explanations below. We report two measures for model fit and improvement. The $R^{2}$ shows that the overall variance explained by our models ranges from 22\% in Model 1 to 32\% in Model 6. Additionally, we report F-tests to document the improvements that the addition of independent variables and interactions make to the model's explanatory power. Models 4-6 take Model 3 as base and show that the inclusion of platform maturity and the interaction terms significantly improves the fit of our models.

\section{--- INSERT TABLE 4 HERE ---}

We focus on Model 4 for the interpretation of our control variables and for the effect of platform maturity on game sales. Control variables all perform as expected. Individual games sell more units when recent platform sales have been higher (platform sales), and when there is a higher ratio of users-togames on the platform. A ten per cent increase in platform sales triggers a $41 \%$ increase in game sales implying that gamers buy multiple games when they adopt a platform $(p<0.01)$. We further find that an increase of 1,000 consumers for every game boosts games' unit sales by nearly $13 \%(p<0.01)$. On the 
other hand, games realize lower sales when many similar competitors launch simultaneously (genre competition), and when games are based on novel IP (new IP). One additional same genre game that enters the platform in the same month of the focal game reduces average unit sales by $2.86 \%(p<0.01)$. This finding supports the "competitive crowding" effect often hypothesized for complementors in platform markets (Boudreau, 2012; Wareham et al., 2014). Similarly, novel IP games see sales that are (on average) 54\% lower than those based on existing IP (either sequels or games with media tie-ins) $(p<$ 0.01). We also see that, as the next generation platform takes more of the market, sales of current generation games realize marginally lower sales $(p<0.05)$.

We find support for $\mathrm{H} 1$ in Model 4. H1 predicts that game sales will decline as the platform matures, after controlling for the effects of competition and the installed base. All else equal, we find that games at the end of the platform lifecycle generate nearly $30 \%$ lower unit sales than games launched early in the platform lifecycle $(p<0.01)$. Our theory suggests that this effect emerges because later adopters spend less on complements, diluting the potentially positive effect of the larger installed base.

We focus on Model 4 for the interpretation of $\mathrm{H} 2$. This hypothesis predicts that the negative effect of new IP will become more severe as the platform matures. Our theory suggests that later adopters of the platform are more risk averse, and are less interested in exploring new IP, compared with early adopters. We test this effect by including an interaction between new IP and platform maturity. We find that the interaction term is negative and significant $(p<0.01)$. At the end of the platform lifecycle, games that are based on novel IP will have $74 \%$ lower unit sales than games that are sequels or based on external media adaptations. It should be noted that the main effect of platform maturity washes out when we include the interaction with New IP. This result suggests that end-users that adopt the platform at late stages of the platform lifecycle are mostly buying games based on existing IP while shying away from more novel offerings. The widening gap between existing and new IP games over the platform lifecycle is shown visually in Figure 2, which strongly supports H2.

\section{--- INSERT FIGURE 2 HERE ---}

In Model 5 we test Hypothesis 4. Our theory predicts that next generation IB will function 
similarly to platform maturity in that both capture the extent to which the pool of potential adopters is more highly skewed towards later adopters of the platform, which we argue are more risk averse. We test H4 by interacting new IP with our measure of next generation installed base. Similar to the interaction between platform maturity and new IP, the interaction with next generation IB is negative and significant $(p<0.01)$. Games released on the existing platform that are based on novel IP sell increasingly fewer units as the next generation platform gains traction. We find that a $10 \%$ increase in the next generation's installed base results in an additional 1.61\% drop in unit sales for games based on new IP. After including the interaction term we note that growth of a next generation installed base primarily affects games based on new IP (rather than games based on existing IP), which is in line with our suggested theory and the assumption that early adopters of a platform will be the first to migrate to a next generation platform of the same type. This gap is shown in Figure 3, and supports H4. In Model 6 we add both interaction terms simultaneously and note no changes to our main results.

--- INSERT FIGURE 3 HERE ---

\section{The Effect of New IP, Platform Maturity, and Next Generation Platforms on Superstar and Flop}

\section{Games}

In Table 5 we compare both tails in the distribution of the dependent variable to assess if the sales disparity between non-popular and popular video games widens as platforms mature (H3) and as the next generation platform gains traction (H5). Using simultaneous quantile regression techniques, we estimate all covariates on $\tau=10$ (non-popular games, or flops) and $\tau=90$ (popular games, or superstars), in Models 1 and 2 respectively. We then take the difference between the coefficients and report these values and their significance levels in Model 3. We report a measure of model fit in the form of a pseudo $R^{2}$. The pseudo $R^{2}$ is calculated as:

$$
1-\frac{\text { sum of weighted deviations about estimated quantile }}{\text { sum of weighted deviations about raw quantile }} .
$$

We explain $21 \%$ of the variance in our estimation of non-popular games (Model 1), and 20\% of the variance in our estimation of superstar games (Model 2). 
--- INSERT TABLE 5 HERE ---

$\mathrm{H} 3$ predicts that as more late adopters adopt a platform, the sales disparity between popular and non-popular complements amplifies. Analogously, H5 predicts that as the next generation platform increases in installed base, the sales disparity between popular and non-popular complements also amplifies. In each case, our theory suggests that the risk aversion and limited information searching habits of later adopters drive the results. The results in Model 1 show that, for non-popular video games $(\tau=10)$, platform maturity $(p<0.01)$ and installed base next generation $(p<0.01)$ have a negative effect on game sales. This suggests that low performing games increasingly fall behind superstar games during later stages of the platform lifecycle. The effect of these variables for superstars in Model 2, however, is not significant. These high performing games perform about the same both early and late in the platform's lifecycle (and before and after the launch of the next generation platform). These results are consistent with $\mathrm{H} 3$ and H5. As late adopters increasingly adopt the platform and comprise of the potential pool of game adopters, game sales will strongly congregate around a few key titles at the cost of other games in the market. Note that platform maturity and next generation IB are the only variables in our models for which the coefficients between superstar and flop games significantly differ. These results are robust to the usage of different thresholds (i.e. Q80-Q20; Q90-Q50)

\section{Alternative Explanations}

Our theoretical explanation for the observed empirical results discussed above hinges on the idea that early adopters of a platform differ significantly from late adopters of the platform, and that these differences affect the performance of complements. When compared with later adopters, early adopters will be more willing to spend on complements, will be more risk-tolerant in terms of new IP, and will be willing to search deeper for lesser-known games instead of simply following the crowd. While the results discussed above are consistent with an explanation based on consumer heterogeneity, we cannot measure consumers directly and so have only indirect evidence. Below we consider a number of alternative explanations for the results, to convince the reader that the results are indeed driven by heterogeneity among consumers. 
First, many potential alternate explanations are ruled out by the direct controls that we include in the model. By controlling for game quality, we can eliminate the potential that games based on new IP are harder to make and thus have lower inherent quality. We can also rule out the idea that, as the platform matures, there is simply more competitive entry by game producers. While this is true, our controls for competitive entry and the stock of games relative to the platform's user-base mean that the observed effect of platform maturity on game sales is after controlling for the effect of competition that play a significant role in Boudreau's work (Boudreau, 2012; Boudreau et al., 2011).

Second, we find similar results using two very different measures of consumer heterogeneity platform maturity and installed base next generation. These two measures capture different factors that are likely to dilute the share of the potential adopter population that are early adopters - the former because early adopters are less numerous than late adopters, and the latter on the theory that early adopters of one generation are likely to be early adopters of the subsequent generation. Not only are these two variables theoretically different, they are only modestly correlated (0.313) in our data. Despite these differences, the results (both main effect and interactions) for the two variables are nearly identical. This provides further evidence that is consistent with consumer heterogeneity-based explanations.

Third, one concern is that our models are inherently cross-sectional, and compare very different types of games to create our results. Publishers may strategically time the release of different types of video games anticipating higher sales volumes. Furthermore, as the costs for acquiring System Development Kits (SDK's) fall over time, producers with substantially smaller production budgets - and subsequently, lower sales thresholds - may seize the opportunity to enter a platform. We address this concern through two approaches - by exploiting the multi-homing nature of many games, and by treating new IP as an endogenous variable. Multi-homing games are those introduced at the same time on more than one competing platform. Since platform maturity is different for each platform even at the same date, we can use a game-level fixed effect specification that works solely off this cross-platform variation in maturity. This approach allows for a relatively clean assessment of the effect of platform maturity. Results for the full subsample of multi-homing games are shown in Model 1 of Table 6. As the results 
show, both platform maturity $(p<0.01)$ and installed base next generation $(p<0.01)$ show a negative and significant effect on game sales. For a single game released on multiple platforms, the game will perform worse on the more mature platform, even after considering the other controls in the model (including platform fixed effects), consistent with H1. By eliminating concerns about unobserved game-level heterogeneity, this game fixed effect specification supports a consumer-driven interpretation of our results. Furthermore, when we split the sample by multi-homing games based on existing IP in Model 2 and multi-homing games based on new IP in Model 3 we find similar results. Notably, the platform maturity and next generation IB coefficients for new IP games are stronger than those for established IP games, which is consistent with $\mathrm{H} 2$ and further validates our theory.

\section{--- INSERT TABLE 6 HERE ---}

Our alternate approach to concerns about the endogeneity of the decision for when to introduce a given game is to use a treatment effects model that controls for the likelihood of any given game being based on new IP as opposed to existing IP. This approach involves a first stage prediction of the likelihood of creating new IP and the inclusion of a treatment hazard in the second stage, similar to a Heckman selection model (except we can observe outcomes for all games, not just those based on novel IP) (Guo \& Fraser, 2009). Following earlier empirical work (Dubé et al., 2010; Gretz \& Basuroy, 2013), we use an exclusion restriction from the first stage to the second, namely the lagged cost of producing video games in the US. ${ }^{11}$ This instrumental variable adheres to good economic practices in that it is correlated with the endogenous regressor, but uncorrelated with the error term of the outcome equation. The results from the treatment regression are reported in Model 7 in Table 4 and are consistent with those reported in Model 6. This suggests that the introduction of new IP may not be endogenous, at least not in

\footnotetext{
${ }^{11}$ We exploit the fact that nearly half of the games $(46 \%)$ in our sample are produced in the US. We obtained data on Producer Price Indexes (PPI) for video game publishing from the Bureau of Labor Statistics as a cost-side instrument. Video game production cycles during the sixth generation game consoles were approximately one year. Hence, we lag PPI games publishing by one year. The assumption is that increases in the cost of making video games in $t_{j}-12$ negatively affect game publishers' willingness to take risks and produce original IP. This assumption is confirmed as the instrumental variable positively affects producers' likelihood of developing new IP games $(p<0.05)$. The instrument is uncorrelated with the outcome equation.
} 
the sense that producers know which new IP games will be successful far enough in advance to intentionally time the date of their launch. This makes sense - the ability to predict which games will be successful with any certainty is quite limited in the video game industry.

Fourth, there are similar concerns about unobserved heterogeneity in terms of new IP games launched at different points in the platform lifecycle. Publishers that successfully establish new intellectual properties may deploy an exploitation strategy by releasing sequels based on their successful franchises, leaving the production of novel games to less shrewd producers. To assess the average treatment effect (ATE) for games that are based on new IP vis-à-vis non-novel games at different stages in the platform lifecycle, we run a splined-sample matched pairs regression. Using propensity score matching (PSM) based on nearest neighbors, we link each new IP video game with their most similar non-novel counterparts within every decile of platform maturity. The coefficients and effect sizes on new $I P$ across different levels of platform maturity are shown in Figure 4. The results show that games based on new IP actually perform very well initially, but realize progressively lower sales compared with established IP games at later periods in the platform's evolution. This matching-based approach helps to alleviate concerns about unobserved differences between novel and non-novel IP games contingent on the stage of the platform lifecycle.

\section{--- INSERT FIGURE 4 HERE ---}

While obviously not conclusive, the combination of clear theoretical predictions, consistent empirical evidence, and an ability to rule out a number of alternate explanations increases confidence that our explanation based on important differences between early and late adopters of the underlying platform is the correct explanation for the results.

\section{Robustness Tests}

Beyond considerations of the alternate explanations discussed above, we have also conducted a number of other robustness checks, each of which produces similar results to those reported in the main results. First, while the entry of competitive games on the market (genre competition) is not the focus of the paper, there are legitimate reasons why the entry of competitive games would be endogenous (Cennamo \& 
Santalo, 2013). We can use a 2SLS approach to endogenize competitive entry (not at the level of the genre, but across all genres) using instruments based on the lagged Producer Price Index (PPI) in the U.S. (Dubé et al., 2010; Gretz \& Basuroy, 2013), and doing so produces results that are similar to those reported here. Second, to eliminate potential biases caused by heterogeneous pricing policies we reestimate all models with an alternative dependent variable. Instead of total unit sales, we consider games' cumulative revenues (in GBP) as a dependent variable. Results are consistent to this alternative DV. Third, we assess the robustness of the results to alternative constructions of the game quality variables. In one approach, we have included average quality scores for each game as a continuous variable, both with and without a dummy for games that did not receive a score. We have also constructed alternate dummybased systems that distinguish only between (for example) highly rated games and all other games. Again, the results are consistent. Fourth, given that we cannot include time fixed effects given their collinearity with our platform maturity variable, we have run models including a large number of macroeconomic factors such as GDP growth, population growth, and other measures. Including these does not change the results substantively. Fifth, we have constructed multiple versions of the next generation IB variable. This includes a simple dummy noting if the next generation console has been launched and the age of the next generation platform. The results are similar. Sixth, we identified which games released at the end of our timeframe are cross-generation compatible (i.e. multi-homing on seventh generation consoles). While we find that these games perform better than other games released in the same timeframe that are not crossgeneration compatible, our main results hold. Seventh, we currently lag both platform sales and genre competition to guard against counter causality. Including those variables measured in the current period, or with longer lags, produces similar results. Finally, we have run quantile regression models that focus on different thresholds for flop and superstar games and the results are consistent. In total, these checks give us strong confidence that our observed results are robust to a number of different approaches and specifications.

\section{Discussion}


We studied the performance of complements in platform markets. The paper's main proposition was that a shifting composition in the platform's user base affects the adoption of complements. The lower willingness to pay and increased risk aversion of late platform adopters means that complements introduced later in a platform's lifecycle will perform worse than those introduced earlier. Moreover, we suggest that these dynamics do not affect all types of complements equally. Late adopters display stronger herding characteristic and search less proactively for novel goods. For these reasons, the disparity between novel (or, innovative) and non-novel complements also widens as platforms mature. Similarly, we conjectured that as platforms mature, there will be a stronger concentration around fewer complements widening the gap in sales between superstars and flops on the platform.

Analyzing a dataset of 2,921 sixth generation console video games in the UK, we found a negative relationship between platform maturity and game sales, particular for games based on original IP. Additionally, using quantile regressions we found that the sales disparity between superstar games $\left(90^{\text {th }}\right.$ quantile $)$ and flops $\left(10^{\text {th }}\right.$ quantile $)$ grew as platforms matured. By showing that these effects also occur as users migrate to the next generation platform, and by controlling for concerns about endogeneity and unobserved heterogeneity through empirical techniques including game-level fixed effects and a treatment effects model, we are confident in suggesting that underlying heterogeneity in the population of potential adopters for a given complement is truly the explanation for the observed empirical results.

The importance of complements on platforms' popularity has been emphasized in extant conceptual and empirical work on two-sided platforms (Schilling 1998; 1999; 2002; Stremersch et al., 2007; Wareham et al., 2014). Moreover, the added impact of superstar complements on the demand side is non-negligible (Binken \& Stremersch, 2009; Lee, 2013). Nevertheless, the study of platform complements is still in its early stages and much work remains to be done in order to build a substantial body of work explaining the adoption of various types of platform complements. We found that complement adoption is affected by demand heterogeneities in the form of end-users entering the platform at different points in time. The approach taken was anchored in, and is supportive of, the emerging body of studies on platforms that shifts focus away from a predominantly price-centered 
approach typically found in economics (Rochet \& Tirole, 2003; 2006). Following work by Gawer (2014), rather than static entities, we approached platforms as dynamic, or as "evolving meta-organizations". The type of dynamism that was investigated in this study adds to our growing understanding of how competition between the providers of complementary goods unfolds as a platform matures.

The paper holds additional implications for demand-side perspectives in management studies. Demand-based perspectives offer a complementary view to the strategy literature that has been criticized for having a "supply-side bias" (Adner, 2002). Customer heterogeneity can help explain competitive outcomes at the product level (Adner \& Levinthal, 2001; Adner \& Zemsky, 2006). Studying products has value for scholars of the resource based view of the firm as it is at the product level where customers assess the value of individual resources and bundles of resources (Lippman \& Rumelt, 2003; Sirmon, Gove \& Hitt 2008; Wernerfelt, 1984). After all, consumers are the final arbiters of value (Bowman \& Ambrosini, 2000; Priem, 2007). We found that consumers' valuations change as the platform matures. Late adopters of a technology adopt fewer complementary goods. Furthermore, they let early adopters' consumption behavior inform their own adoption decisions. These demand-side shifts moderate the impact of indirect network effects and affect competitive outcomes for complements in platform markets. Besides these theoretical implications, our findings have additional implications for firms' resource deployment and resource bundling strategies, adding further validity to the value of demand-based perspectives in strategy and technology innovation studies.

Finally, our study has important managerial implications as illustrated by the example of Watch Dogs. In May 2014, Ubisoft released its highly anticipated action adventure video game Watch Dogs on four platforms spanning two generations of consoles. The innovative game faced an addressable audience of over 160 million seventh generation platform adopters (PlayStation 3 and Xbox 360) and just shy of 13 million eight generation platform adopters (PlayStation 4 and Xbox One). Despite this gap in installed bases, over two thirds of the game's eight million units sold occurred on eight generation platforms (Ubisoft, 2014). Our results help explain Watch Dogs' surprising performance and simultaneously inform managerial decision making. First, contrary to commonly held managerial perceptions, results show that 
launching complements early in a platform's lifecycle when the installed base has not yet reached its full potential may not dampen success. Secondly, complementors should carefully balance their exploration and exploitation efforts contingent on a platform's maturity. Results indicate that innovation for complements yields higher sales performance at early stages in a platform's lifecycle. Thirdly, the results hold implications for complementors' portfolio management. Since the adoption disparity between popular and less popular complements increases as platforms mature, complementors are advised to allocate greater resources towards fewer goods to increase their chances of success.

\section{References}

Abernathy WJ, Utterback JM (1978) Patterns of industrial innovation. Technology Review. 64: 254-228.

Adner R, Kapoor R (2015) Innovation ecosystems and the pace of substitution: Re-examining technology S-curves. Strategic Management Journal. Forthcoming.

Adner R, Kapoor R (2010) Value creation in innovation ecosystems: How the structure of technological interdependence affects firm performance in new technology generations. Strategic Management Journal. 31(3): 306-333.

Adner R, Levinthal D (2001) Demand heterogeneity and technology evolution: Implications for product and process innovation. Management Science. 47(5): 611-628.

Adner R, Snow D (2010) Old technology responses to new technology threats: Demand heterogeneity and technology retreats. Industrial and Corporate Change. 19(5): 1655-1675.

Adner R, Zemsky P (2006) A demand-based perspective on sustainable competitive advantage. Strategic Management Journal. 27(3): 215-239.

Adner R (2002) When are technologies disruptive? A demand-based view of the emergence of competition. Strategic Management Journal. 23(8): 667-688.

Ahuja G, Lampert CM, Tandon V (2008) Moving beyond Schumpeter: Management research on the determinants of technological innovation. The Academy of Management Annals. 2(1): 1-98.

Andersen S, Harrison G, Lau M, Rutstrom E (2008) Lost in state space: Are preferences stable? International Economic Review. 49(3): 1091-1112.

Arthur WB (1989) Competing technologies, increasing returns, and lock-in by historical events. The economic journal. 116-131.

Binken JL, Stremersch S (2009) The effect of superstar software on hardware sales in system markets. Journal of Marketing. 73(2): 88-104.

Boudreau KJ, Jeppesen LB (2014). Unpaid crowd complementors: The platform network effect mirage. Strategic Management Journal. Forthcoming.

Boudreau KJ, Lacetera N, Lakhani KR (2011) Incentives and problem uncertainty in innovation contests: An empirical analysis. Management Science. 57(5): 843-863.

Boudreau KJ (2012) Let a thousand flowers bloom? An early look at large numbers of software app developers and patterns of innovation. Organization Science. 23(5): 1409-1427.

Bowman C, Ambrosini V (2000) Value creation versus value capture: Towards a coherent definition of value in strategy. British Journal of Management. 11(1): 1-15.

Nalebuff BJ, Brandenburger A, Maulana A (1996) Co-opetition. London: HarperCollinsBusiness.

Cabral LM (1990) On the adoption of innovations with 'network' externalities. Mathematical Social Sciences. 19(3): 299-308. 
Cennamo C, Santalo J (2013) Platform competition: Strategic trade-offs in platform markets. Strategic Management Journal. 34(11): 1331-1350.

Chau PYK, Hui KL (1998) Identifying early adopters of new IT products: A case of Windows 95. Information \& Management. 33(5): 225-230.

Clements MT, Ohashi H (2005) Indirect network effects and the product lifecycle: Video games in the US, 1994-2002. The Journal of Industrial Economics. 53(4): 515-542.

Corts KS, Lederman M (2009) Software exclusivity and the scope of indirect network effects in the US home video game market. International Journal of Industrial Organization. 27(2): 121-136.

Dosi G (1982) Technological paradigms and technological trajectories: A suggested interpretation of the determinants and directions of technical change. Research Policy. 11(3): 147-162.

Dring C (2013) GTA V UK sales bigger than Battlefield, FIFA, Call of Duty, Batman, Pokemon and Assassin's Creed combined. MCV. November, 2015.

Dubé JPH, Hitsch GJ, Chintagunta PK (2010) Tipping and concentration in markets with indirect network effects. Marketing Science. 29(2): 216-249.

Ehrenberg AS, Goodhardt GJ, Barwise TP (1990). Double jeopardy revisited. Journal of Marketing. 8291.

Einav L (2007) Seasonality in the US motion picture industry. RAND Journal of Economics. 127-145.

Elberse A, Oberholzer-Gee F (2008). Superstars and underdogs: An examination of the long tail phenomenon in video sales. MSI Reports: Working Paper Series. 4: 49-72.

ESA (2013) Essential Facts About the Computer and Video Game Industry. ESA. November, 2015.

Fleder D, Hosanagar K (2009) Blockbuster culture's next rise or fall: The impact of recommender systems on sales diversity. Management Science. 55(5): 697-712.

Gartner (2013) Gartner Says Worldwide Video Game Market to Total $\$ 93$ Billion in 2013. Gartner. November, 2015.

Gawer A, Cusumano MA (2014) Industry platforms and ecosystem innovation. Journal of Product Innovation Management. 31(3): 417-433.

Gawer A (2014) Bridging differing perspectives on technological platforms: Toward an integrative framework. Research Policy. 43(7): 1239-1249.

Geroski PA (2000) Models of technology diffusion. Research policy. 29(4): 603-625.

Golder PN, Tellis GJ (2004) Growing, growing, gone: Cascades, diffusion, and turning points in the product life cycle. Marketing Science. 23(2): 207-218.

Gretz RT, Basuroy S (2013) Why quality may not always win: The impact of product generation life cycles on quality and network effects in high-tech markets. Journal of Retailing. 89(3): 281-300.

Guo SY, Fraser MW (2009) Propensity Score Analysis: Statistical Methods and Applications (Advanced Quantitative Techniques in the Social Sciences). SAGE Publications, NY.

Hagiu A, Spulber D (2013) First-party content and coordination in two-sided markets. Management Science. 59(4): 933-949.

Harrison G, Johnson E, McInnes M, Rutstrom E (2005) Temporal stability of estimates of risk aversion. Applied Financial Economic Letters. 1(1): 31-35.

Huh YE, Kim SH (2008) Do early adopters upgrade early? Role of post-adoption behavior in the purchase of next-generation products. Journal of Business Research. 61(1): 40-46.

IDG (2011) IDG Global Forecast Update. Trade publication.

Johns J (2006) Video games production networks: Value capture, power relations and embeddedness. Journal of Economic Geography. 6(2): 151-180.

Juul J (2010) A casual revolution. Reinventing Video Games and Their Players. Cambridge, MA.

Kah JA, Vogt C, MacKay K (2008) Online travel information search and purchasing by internet use experiences. Information Technology \& Tourism. 10(3): 227-243.

Karshenas M, Stoneman PL (1993) Rank, stock, order, and epidemic effects in the diffusion of new process technologies: An empirical model. The RAND Journal of Economics. 503-528.

Katz ML, Shapiro C (1994) Systems competition and network effects. The Journal of Economic Perspectives. 93-115. 
Katz ML, Shapiro C (1986) Technology adoption in the presence of network externalities. The Journal of Political Economy. 822-841.

Kim JH, Prince J, Qiu C (2014) Indirect network effects and the quality dimension: A look at the gaming industry. International Journal of Industrial Organization. 37: 99-108.

Kleinschmidt EJ, Cooper RG (1991) The impact of product innovativeness on performance. Journal of Product Innovation Management. 8(4): 240-251.

Klepper S (1997) Industry life cycles. Industrial and corporate change. 6: 145-182.

Koenker R, Bassett Jr G (1978) Regression quantiles. Econometrica. 33-50.

Kretschmer T, Grajek M (2009) Usage and diffusion of cellular telephony, 1998-2004. International Journal of Industrial Organization. 27(2): 238-249.

Landsman V, Stremersch S (2011) Multihoming in two-sided markets: An empirical inquiry in the video game console industry. Journal of Marketing. 75(6): 39-54.

Lee RS (2013) Vertical integration and exclusivity in platform and two-sided markets. The American Economic Review. 103(7): 2960-3000.

Leonard-Barton D, Kraus WA (1985) Implementing new technology. Harvard Business Review. 63(6).

Lippman SA, Rumelt RP (2003) A bargaining perspective on resource advantage. Strategic Management Journal. 24(11): 1069-1086.

McPhee WN (1963) Formal Theories of Mass Behavior. New York: Free Press of Glencoe.

Metacritic (2015) How We Create the Metascore Magic. Metacritic. November, 2015.

Morris C (2012) Ubisoft's Guillemot: New consoles are overdue. Gamasutra. November, 2015.

Parker GG, Van Alstyne MW (2005) Two-sided network effects: A theory of information product design. Management Science. 51(10): 1494-1504.

Priem RL (2007) A consumer perspective on value creation. Academy of Management Review. 32(1): 219-235.

Rochet JC, Tirole J (2006) Two-sided markets: A progress report. The RAND Journal of Economics. 37(3): 645-667.

Rochet JC, Tirole J (2003) Platform competition in two-sided markets. Journal of the European Economic Association. 1(4): 990-1029.

Rogers EM (2003) Diffusion of Innovations. Simon and Schuster.

Schilling MA (2002) Technology success and failure in winner-take-all markets: The impact of learning orientation, timing, and network externalities. Academy of Management Journal. 45(2): 387-398.

Schilling MA (1999) Winning the standards race: Building installed base and the availability of complementary goods. European Management Journal. 17(3): 265-274.

Schilling MA (1998) Technological lockout: An integrative model of the economic and strategic factors driving technology success and failure. Academy of Management Review. 23(2): 267-284.

Sirmon DG, Gove S, Hitt MA (2008) Resource management in dyadic competitive rivalry: The effects of resource bundling and deployment. Academy of Management Journal. 51(5): 919-935.

Stremersch S, Tellis GJ, Franses PH, Binken JL (2007) Indirect network effects in new product growth. Journal of Marketing. 71(3): 52-74.

Tschang FT (2007) Balancing the tensions between rationalization and creativity in the video games industry. Organization Science. 18(6): 989-1005.

Ubisoft (2014) Earnings call first half of 2014. Ubisoft Investor Center. October, 2014.

Utterback JM, Abernathy WJ (1975) A dynamic model of process and product innovation. Omega. 3(6): 639-656.

Venkatraman N, Lee CH (2004) Preferential linkage and network evolution: A conceptual model and empirical test in the US video game sector. Academy of Management Journal. 47(6): 876-892.

Von Hippel E (1986) Lead users: A source of novel product concepts. Management Science. 32(7): 791805.

Wareham J, Fox PB, Cano Giner JL (2014) Technology Ecosystem Governance. Organization Science. 25(4): 1195-1215.

Wernerfelt B (1984) A resource-based view of the firm. Strategic Management Journal. 5(2): 171-180. 


\section{TABLES \& FIGURES}

Table 1. Sixth Generation Video Game Consoles in the UK (2000-2007)

\begin{tabular}{lccccccc}
\hline $\begin{array}{l}\text { Video Game } \\
\text { Console }\end{array}$ & $\begin{array}{c}\text { Platform } \\
\text { Owner }\end{array}$ & $\begin{array}{c}\text { UK } \\
\text { Introduction }\end{array}$ & $\begin{array}{c}\text { Platform } \\
\text { Lifecycle }\end{array}$ & $\begin{array}{c}\text { UK Launch } \\
\text { Price (GBP) }\end{array}$ & $\begin{array}{c}\text { UK Installed } \\
\text { Base (1000) }\end{array}$ & $\begin{array}{c}\text { Game } \\
\text { Launches }\end{array}$ & $\begin{array}{c}\text { Next Gen. } \\
\text { Introduced (UK) }\end{array}$ \\
\hline PS 2 & Sony & November 2000 & 84 months & $£$ & 299.99 & 9,083 & 1,775 \\
Xbox & Microsoft & March 2002 & 57 months & $£$ & 299.99 & 3,110 & 738 \\
GameCube & Nintendo & May 2002 & 48 months & $£$ & 129.99 & 1,050 & Novem 2007 \\
\hline
\end{tabular}

Table 2. Measures \& Operationalizations

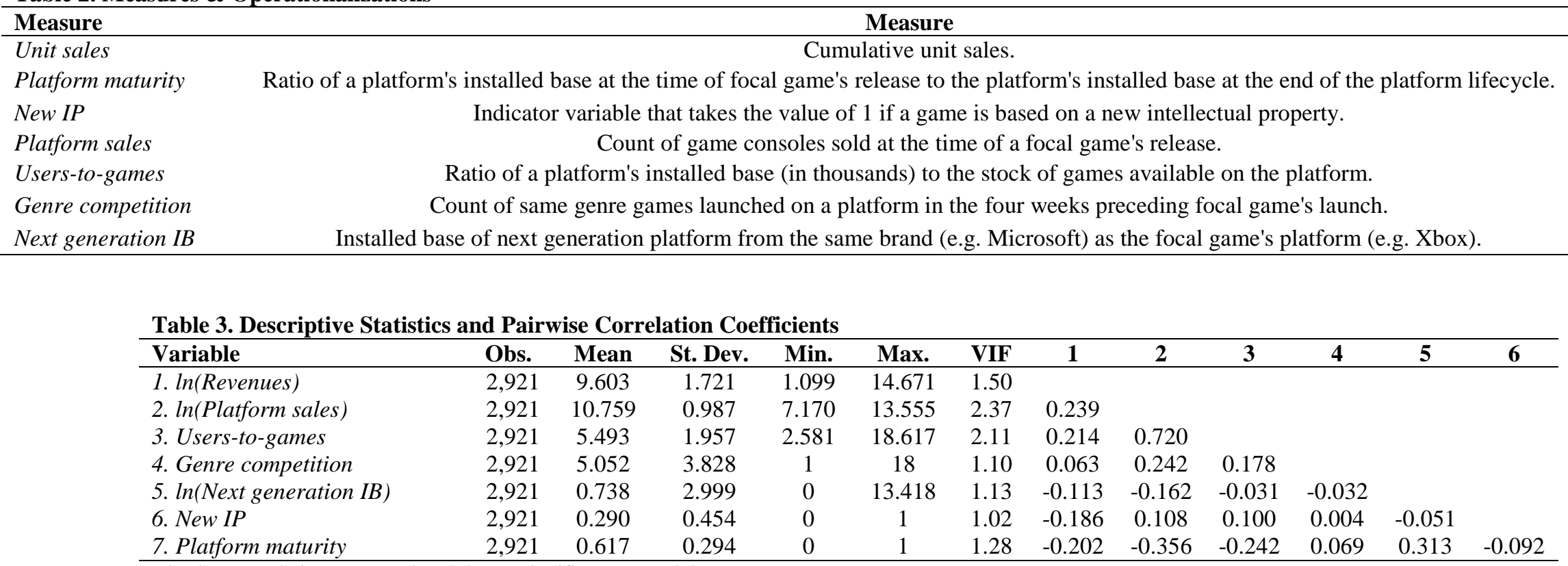

Unit of analysis

Game-platform

Platform-month

Game

Platform-month

Platform-month

Game-platform

Platform-month

Absolute correlations greater than 0.05 are significant at $p<0.05$. 
Table 4. The Effect of New IP, Platform Maturity, and Next Generation IB on Game Sales

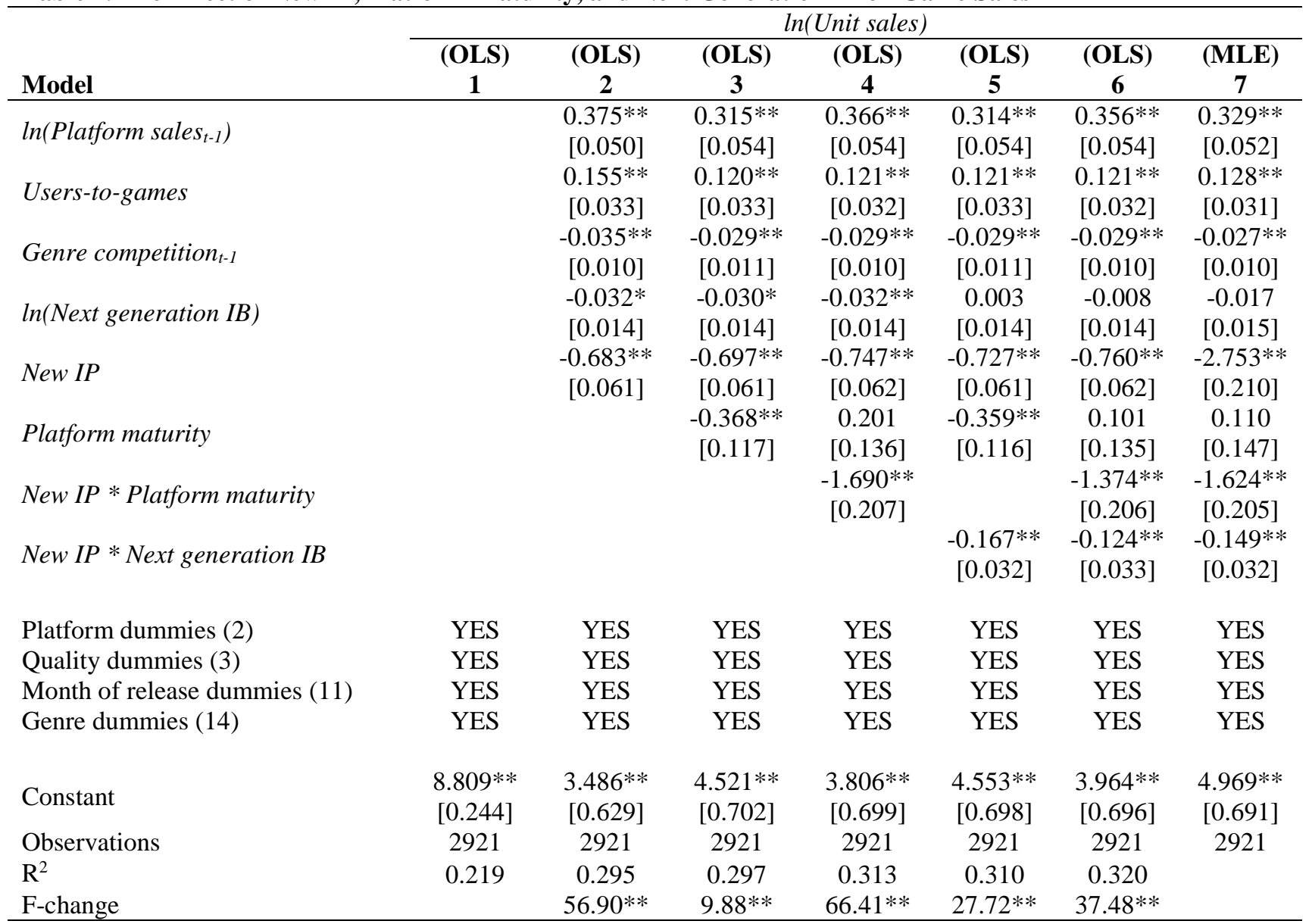

$* * p<0.01, * p<0.05,+p<0.10$.

Models 1-6: OLS regressions of games' logged unit sales. F-statistics for models 4, 5, and 6 are calculated using model 3 as base. Model 7: Treatment effects model of New IP estimated with instrumental variable. Exclusion restriction is the lagged cost of video game development in US $(0.076: p<0.05))$.

Platform maturity and Next generation IB are mean-centered to facilitate interpretation of interactions.

Heteroskedasticity robust standard errors reported in parentheses. 
Table 5. The Effect of New IP, Platform Maturity, and Next Generation IB on Superstars and Flop Games

\begin{tabular}{|c|c|c|c|}
\hline \multirow{3}{*}{ Model } & \multicolumn{3}{|c|}{ Simultaneous Quantile Regressions } \\
\hline & (Q10) & (Q90) & (Q90-Q10) \\
\hline & 1 & 2 & 3 \\
\hline \multirow{2}{*}{$\ln \left(\right.$ Platform sales $\left._{t-1}\right)$} & $0.339 * *$ & $0.250 * *$ & -0.089 \\
\hline & {$[0.112]$} & {$[0.066]$} & {$[0.135]$} \\
\hline \multirow{2}{*}{ Users-to-games } & $0.159 *$ & $0.142 * *$ & -0.017 \\
\hline & {$[0.072]$} & {$[0.044]$} & {$[0.076]$} \\
\hline \multirow{2}{*}{ Genre competition $_{t-1}$} & $-0.038+$ & -0.006 & 0.032 \\
\hline & {$[0.022]$} & {$[0.014]$} & {$[0.024]$} \\
\hline \multirow{2}{*}{$\ln ($ Next generation IB $)$} & $-0.096 * *$ & -0.014 & $0.110 * *$ \\
\hline & {$[0.030]$} & {$[0.002]$} & {$[0.035]$} \\
\hline \multirow{2}{*}{ New IP } & $-0.553 * *$ & $-0.478 * *$ & 0.076 \\
\hline & {$[0.119]$} & {$[0.103]$} & [0.149] \\
\hline \multirow{2}{*}{ Platform maturity } & $-0.888 * *$ & 0.259 & $1.147 * *$ \\
\hline & {$[0.224]$} & {$[0.165]$} & {$[0.225]$} \\
\hline Platform dummies (2) & YES & YES & YES \\
\hline Quality dummies (3) & YES & YES & YES \\
\hline Month of release dummies (11) & YES & YES & YES \\
\hline Genre dummies (14) & YES & YES & YES \\
\hline \multirow{2}{*}{ Constant } & 2.375 & $6.866^{*}$ & $4.491 *$ \\
\hline & [1.481] & {$[0.960]$} & {$[1.875]$} \\
\hline Observations & 2921 & 2921 & 2921 \\
\hline Pseudo $\mathrm{R}^{2}$ & 0.212 & 0.198 & \\
\hline
\end{tabular}

$* * p<0.01, * p<0.05,+p<0.10$

Standard errors calculated using the bootstrapping method (100 replications).

Model 3 estimates interquantile range coefficients, or the difference in quantiles (Q90 - Q10). Interquantile results are robust to alternative quantiles (e.g. Q80-Q20; Q90-Q50).
Table 6. Using Game Fixed Effects to Control for

Unobserved Heterogeneity

\begin{tabular}{|c|c|c|c|}
\hline Model & $\begin{array}{c}\text { All games } \\
\left(\begin{array}{c}\text { OLS }) \\
1\end{array}\right.\end{array}$ & $\begin{array}{c}\text { Existing IP } \\
\text { (OLS) } \\
2\end{array}$ & $\begin{array}{c}\text { New IP } \\
\text { (OLS) } \\
\mathbf{3}\end{array}$ \\
\hline In(Platform sales Pl-1 $)$ & $\begin{array}{l}0.428 * * \\
{[0.061]}\end{array}$ & $\begin{array}{c}0.490 * * \\
{[0.060]}\end{array}$ & $\begin{array}{c}0.050 \\
{[0.137]}\end{array}$ \\
\hline Users-to-games & $\begin{array}{c}0.061 \\
{[0.051]}\end{array}$ & $\begin{array}{c}0.003 \\
{[0.066]}\end{array}$ & $\begin{array}{c}0.268 * * \\
{[0.079]}\end{array}$ \\
\hline Genre competition $_{t-1}$ & $\begin{array}{c}0.014 \\
{[0.012]}\end{array}$ & $\begin{array}{c}0.011 \\
{[0.013]}\end{array}$ & $\begin{array}{c}-0.000 \\
{[0.023]}\end{array}$ \\
\hline $\ln ($ Next generation IB $)$ & $\begin{array}{c}-0.030 * * \\
{[0.011]}\end{array}$ & $\begin{array}{l}-0.022 * \\
{[0.010]}\end{array}$ & $\begin{array}{c}-0.102 * * \\
{[0.017]}\end{array}$ \\
\hline Platform maturity & $\begin{array}{c}-1.637 * * \\
{[0.367]}\end{array}$ & $\begin{array}{c}-1.303 * \\
{[0.522]}\end{array}$ & $\begin{array}{r}-1.667 * * \\
{[0.509]}\end{array}$ \\
\hline $\begin{array}{l}\text { Platform dummies } \\
\text { Game dummies }\end{array}$ & $\begin{array}{l}\text { YES } \\
\text { YES }\end{array}$ & $\begin{array}{l}\text { YES } \\
\text { YES }\end{array}$ & $\begin{array}{l}\text { YES } \\
\text { YES }\end{array}$ \\
\hline Constant & $\begin{array}{c}6.507 * * \\
{[1.062]}\end{array}$ & $\begin{array}{c}6.298 * * \\
{[0.820]}\end{array}$ & $\begin{array}{c}7.980 * * \\
{[1.945]}\end{array}$ \\
\hline $\begin{array}{l}\text { Game-platform obs. } \\
\text { Games } \\
\mathrm{R}^{2}\end{array}$ & $\begin{array}{c}1519 \\
640 \\
0.898\end{array}$ & $\begin{array}{c}1169 \\
479 \\
0.906\end{array}$ & $\begin{array}{c}350 \\
161 \\
0.902\end{array}$ \\
\hline
\end{tabular}

Game fixed effect regressions on subsamples of multi-homing video games (1), multi-homing video games based on existing IP (2), and multi-homing video games based on new IP (3).

Heteroskedasticity robust standard errors in parentheses. 
Figure 1. Game Launches over the Platform Lifecycle

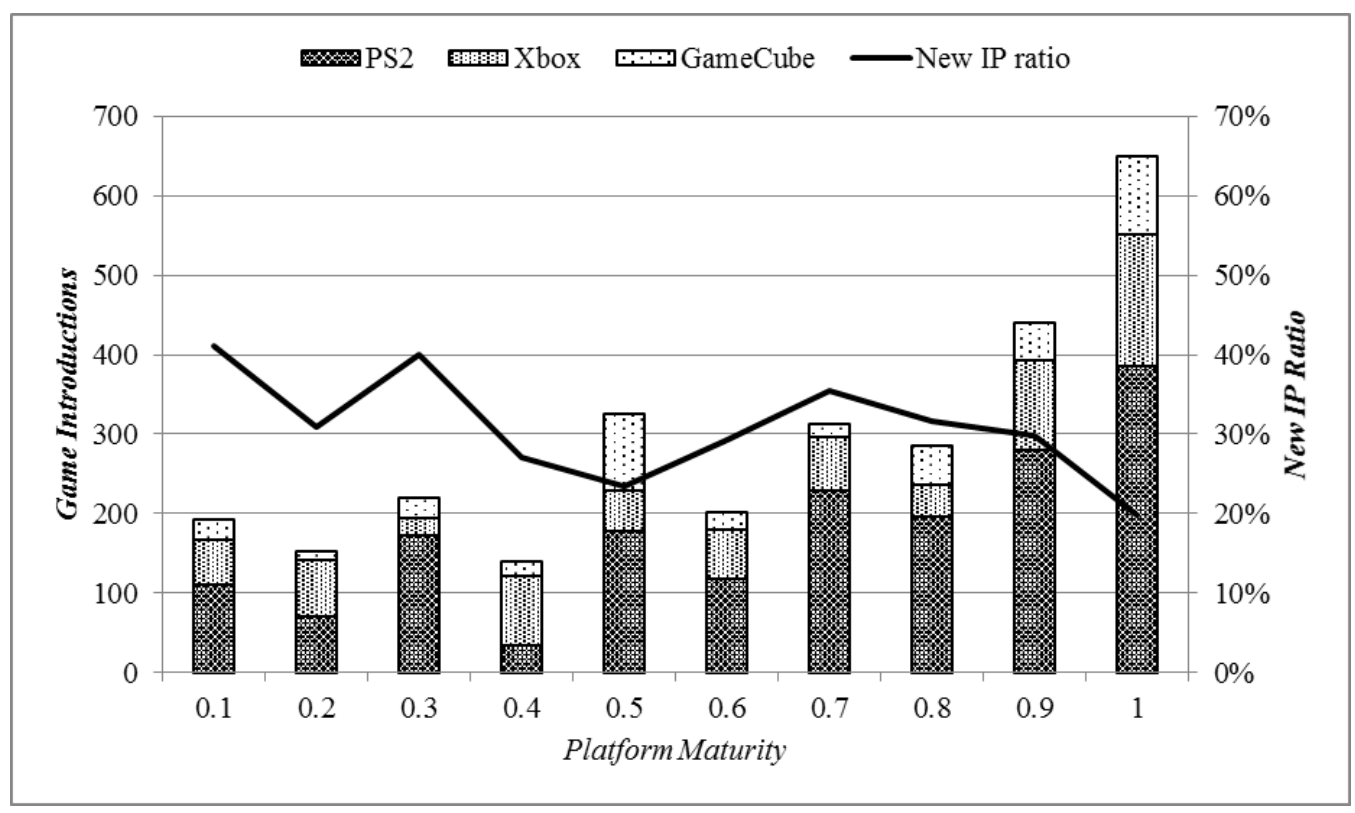

Figure 2. The Effect of Platform Maturity on Sales by Game Type

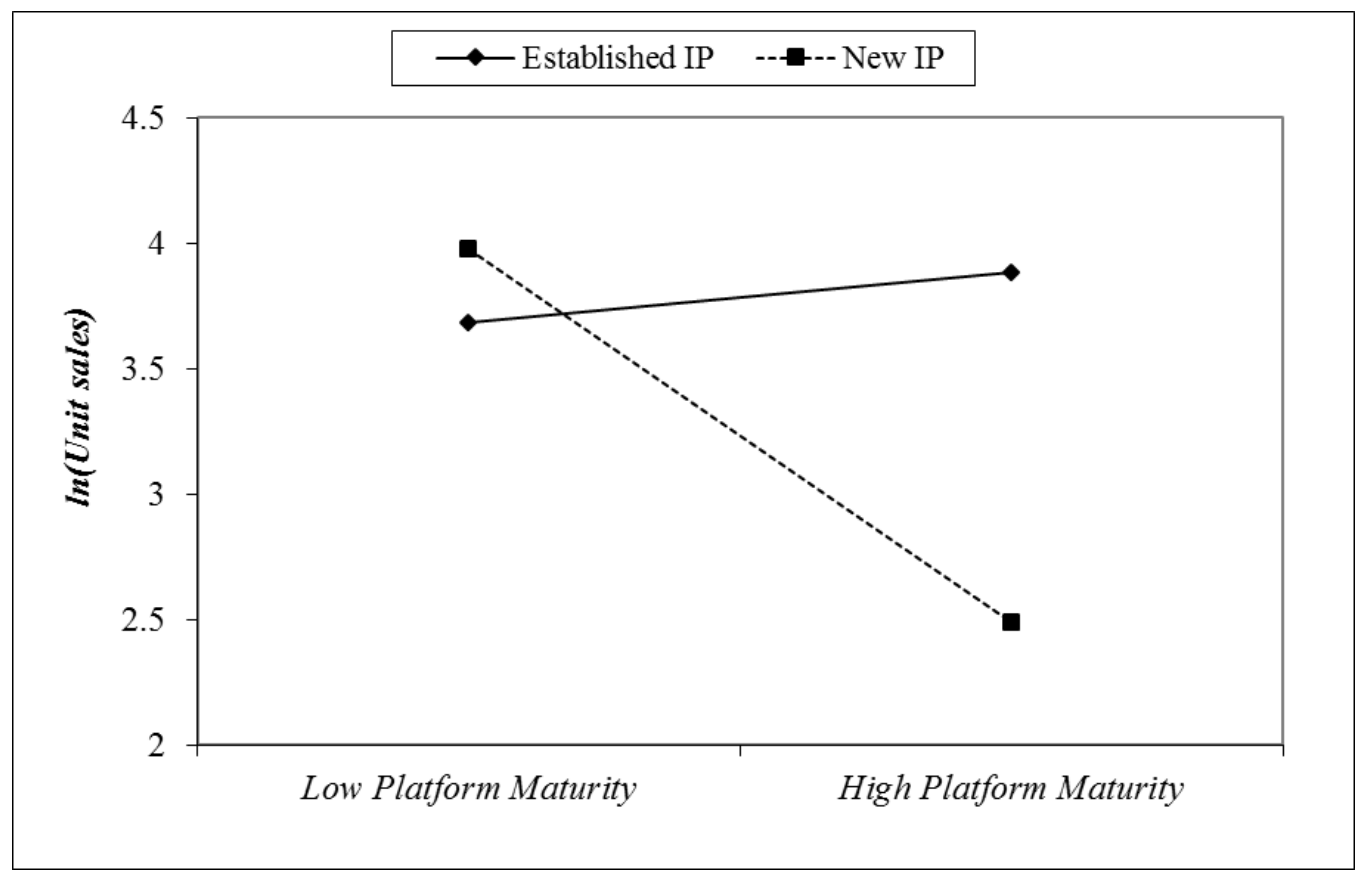


Figure 3. The Effect of Next Generation IB on Sales by Game Type

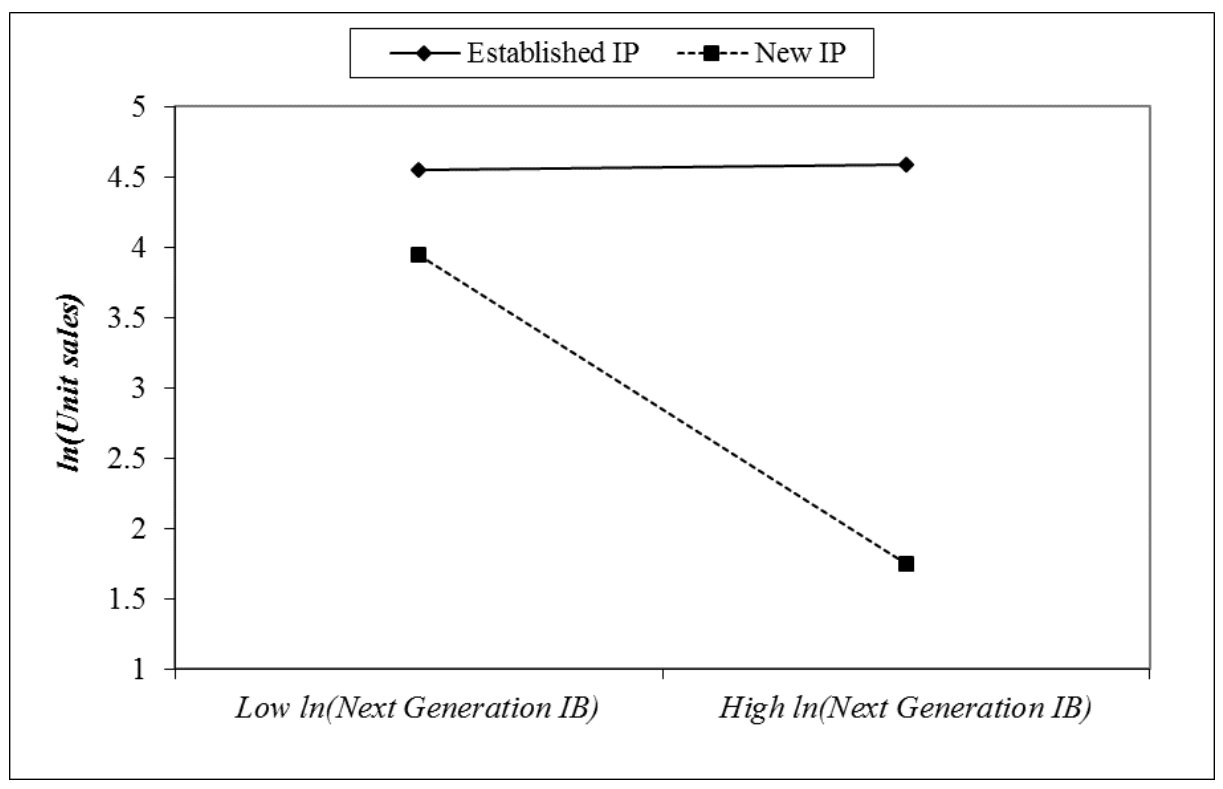

Figure 4. Matched Sample Treatment Effects of New IP on Game Sales ${ }^{12}$

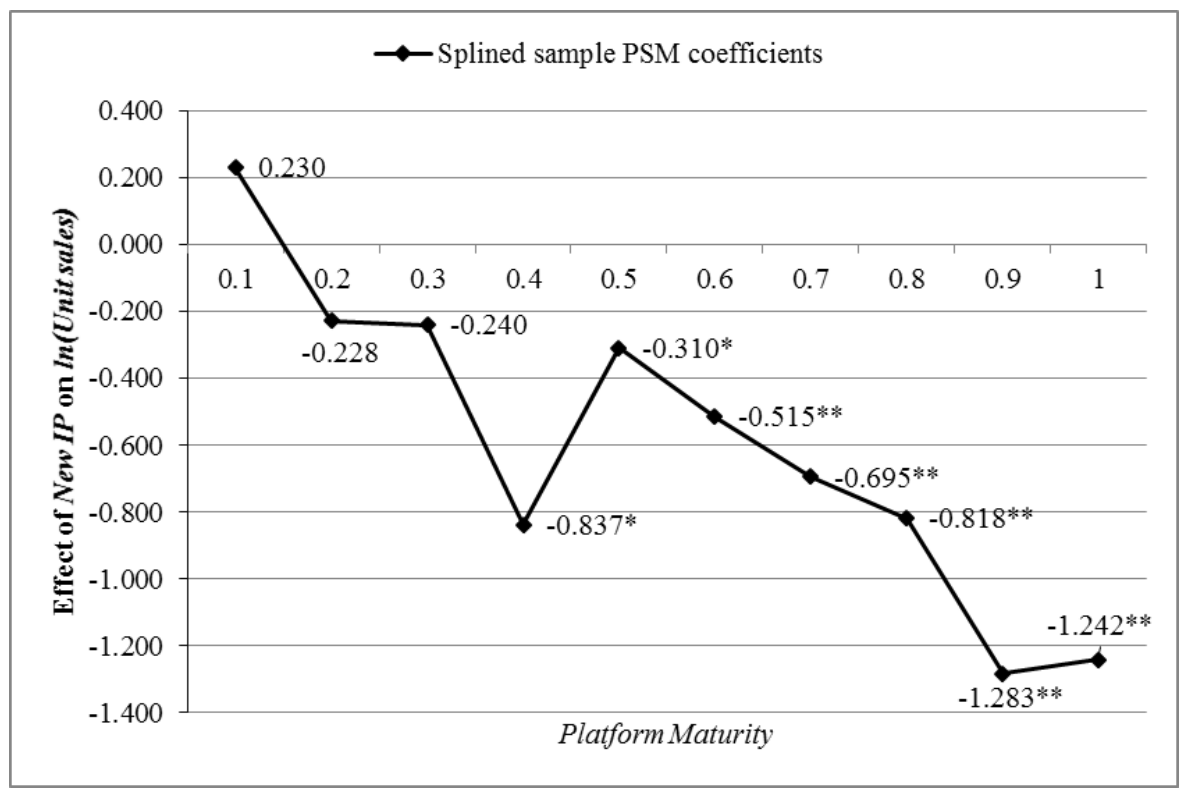

${ }^{12}$ The effect of new IP games on unit sales from splined-sample PSM regressions based on nearest neighbors matching. Sample split in platform maturity deciles (full sample treatment effect for the PSM regression is $=0.741$ : $p<0.01$ ). Matching variables include In(Platform sales), Users-to-games, Genre competition, In(Installed base), Platform maturity, and platform, quality, calendar month, and genre fixed effects. Estimated with heteroskedasticity robust standard errors. Coefficients and significance levels reported $(+p<0.10 ; * p<0.05 ; * * p<0.01)$. 